Cochrane Database of Systematic Reviews

\title{
Mannitol for acute traumatic brain injury (Review)
}

Wakai A, McCabe A, Roberts I, Schierhout G

Wakai A, McCabe A, Roberts I, Schierhout G.

Mannitol for acute traumatic brain injury.

Cochrane Database of Systematic Reviews 2013, Issue 8. Art. No.: CD001049.

DOI: 10.1002/14651858.CD001049.pub5.

www.cochranelibrary.com 
TABLE OF CONTENTS

HEADER 1

ABSTRACT

PLAIN LANGUAGE SUMMARY

BACKGROUND

OBJECTIVES

METHODS

RESULTS

Figure 1.

Figure 2.

DISCUSSION

AUTHORS' CONCLUSIONS

REFERENCES

CHARACTERISTICS OF STUDIES

DATA AND ANALYSES

Analysis 1.1. Comparison 1 ICP-directed mannitol ('treatment') compared to mannitol according to neurological signs

('control'), Outcome 1 Death.

Analysis 1.2. Comparison 1 ICP-directed mannitol ('treatment') compared to mannitol according to neurological signs ('control'), Outcome 2 Death or severe disability.

Analysis 2.1. Comparison 2 Mannitol versus pentobarbital, Outcome 1 Death.

Analysis 3.1. Comparison 3 Mannitol versus hypertonic saline, Outcome 1 Death.

Analysis 4.1. Comparison 4 Mannitol versus placebo, Outcome 1 Death.

APPENDICES

FEEDBACK

WHAT'S NEW

HISTORY

CONTRIBUTIONS OF AUTHORS

DECLARATIONS OF INTEREST

SOURCES OF SUPPORT

INDEX TERMS 
[Intervention Review]

\section{Mannitol for acute traumatic brain injury}

Abel Wakai1 ${ }^{1}$, Aileen McCabe ${ }^{1}$, Ian Roberts ${ }^{2}$, Gillian Schierhout ${ }^{3}$

1Emergency Care Research Unit (ECRU), Division of Population Health Sciences (PHS), Royal College of Surgeons in Ireland, Dublin 2, Ireland. ${ }^{2}$ Cochrane Injuries Group, London School of Hygiene \& Tropical Medicine, London, UK. ${ }^{3}$ c/o Cochrane Injuries Group, London School of Hygiene \& Tropical Medicine, London, UK

Contact address: Abel Wakai, Emergency Care Research Unit (ECRU), Division of Population Health Sciences (PHS), Royal College of Surgeons in Ireland, 123 St. Stephen's Green, Dublin 2, Ireland. awakai@rcsi.ie, abelwakai@gmail.com.

Editorial group: Cochrane Injuries Group

Publication status and date: Edited (no change to conclusions), published in Issue 8, 2013.

Citation: Wakai A, McCabe A, Roberts I, Schierhout G. Mannitol for acute traumatic brain injury. Cochrane Database of Systematic Reviews 2013, Issue 8. Art. No.: CD001049. DOI: 10.1002/14651858.CD001049.pub5.

Copyright @ 2013 The Cochrane Collaboration. Published by John Wiley \& Sons, Ltd.

\section{A B S T R A C T}

\section{Background}

Mannitol is sometimes effective in reversing acute brain swelling, but its effectiveness in the ongoing management of severe head injury remains unclear. There is evidence that, in prolonged dosage, mannitol may pass from the blood into the brain, where it might cause increased intracranial pressure.

\section{Objectives}

To assess the effects of different mannitol therapy regimens, of mannitol compared to other intracranial pressure (ICP) lowering agents, and to quantify the effectiveness of mannitol administration given at other stages following acute traumatic brain injury.

\section{Search methods}

We searched the Cochrane Injuries Group Specialised Register, CENTRAL (The Cochrane Library), MEDLINE (OvidSP), EMBASE (OvidSP), ISI Web of Science (SCI-EXPANDED \& CPCI-S) and PubMed. We checked reference lists of trials and review articles, and contacted authors of trials. The search was updated on the 20th April 2009.

\section{Selection criteria}

Randomised controlled trials of mannitol, in patients with acute traumatic brain injury of any severity. The comparison group could be placebo-controlled, no drug, different dose, or different drug. We excluded cross-over trials, and trials where the intervention was started more than eight weeks after injury.

\section{Data collection and analysis}

We independently rated quality of allocation concealment and extracted the data. Relative risks (RR) and 95\% confidence intervals (CI) were calculated for each trial on an intention to treat basis.

\section{Main results}

We identified four eligible randomised controlled trials. One trial compared ICP-directed therapy to 'standard care' (RR for death = 0.83; $95 \% \mathrm{Cl} 0.47$ to 1.46 ). One trial compared mannitol to pentobarbital (RR for death $=0.85 ; 95 \% \mathrm{Cl} 0.52$ to 1.38 ). One trial compared mannitol to hypertonic saline (RR for death $=1.25 ; 95 \% \mathrm{Cl} 0.47$ to 3.33). One trial tested the effectiveness of pre-hospital administration of mannitol against placebo (RR for death $=1.75 ; 95 \% \mathrm{Cl} 0.48$ to 6.38 ). 


\section{Authors' conclusions}

Mannitol therapy for raised ICP may have a beneficial effect on mortality when compared to pentobarbital treatment, but may have a detrimental effect on mortality when compared to hypertonic saline. ICP-directed treatment shows a small beneficial effect compared to treatment directed by neurological signs and physiological indicators. There are insufficient data on the effectiveness of pre-hospital administration of mannitol.

\section{PLAIN LANGUAGE SUMMARY}

\section{Mannitol for acute traumatic brain injury}

Mannitol is a sugar alcohol solution which is sometimes effective in reducing brain swelling after head injury. However, its effectiveness in the ongoing treatment of severe head injury remains unclear. There is evidence that excessive administration of mannitol may be harmful, by mannitol passing from the bloodstream into the brain, where it increases pressure within the skull and worsens brain swelling. The review authors searched the medical literature and identified four randomized controlled trials comparing mannitol to other treatment strategies for reducing brain swelling after head injury. One trial compared treatment with mannitol directed by measurement of the pressure within the skull (intracranial pressure) with 'standard treatment' (treatment without measurement of intracranial pressure). One trial compared treatment with mannitol to treatment with pentobarbital (a barbiturate drug). One trial compared treatment with mannitol to treatment with hypertonic saline (highly concentrated salt solution). One trial compared treatment with mannitol to treatment with placebo (an inactive 'dummy' solution) before arrival in the hospital (pre-hospital). The review found that treatment with mannitol for increased intracranial pressure reduced the likelihood of death when compared to treatment with pentobarbital. In contrast, it found that treatment with mannitol may increase the likelihood of death when compared to treatment with hypertonic saline. The review also found a small benefit when mannitol treatment is directed by measurement of intracranial pressure compared to 'standard treatment.' The review found insufficient data on the effectiveness of pre-hospital administration of mannitol. 


\section{B A C K G R O U N D}

Mannitol is widely used in the control of raised intracranial pressure following brain injury. A 1995 survey of the critical care management of head-injured patients in the United States showed that $83 \%$ of centres used osmotic diuretics in more than half of severely head-injured patients (Ghajar 1995). A survey in the United Kingdom showed that $100 \%$ of neurosurgical centres used mannitol in the treatment of raised intracranial pressure (Jeevaratnam 1996; Matta 1996). The effectiveness of mannitol for head-injured patients in a critical condition is considered to be well established, without the need for randomised controlled trials.

For other patients, the Brain Trauma Foundation Guidelines Task Force of the American Association of Neurological Surgeons and Joint Section in Neurotrauma and Critical Care (Task Force 1995) recommend that mannitol be used only if the patient has signs of raised intracranial pressure (ICP) or deteriorating neurological status. In these circumstances, any adverse effects are most likely to be outweighed by therapeutic benefit. Nevertheless, the guidelines acknowledge that this is an area of considerable clinical uncertainty. There is uncertainty over the optimal treatment regimen, over the effectiveness of mannitol as compared to other ICP-lowering agents and over the usefulness of mannitol given at other stages following head injury, for example in the pre-hospital setting, prior to volume resuscitation.

We conducted a systematic review of randomised controlled trials that compared different mannitol treatment regimens, or compared mannitol to alternative interventions or placebo, at any stage in the acute management of head injury.

\section{O B J E C T IVES}

1. To compare the effectiveness of mannitol therapy when given in different doses and for different durations.

2. To quantify the effectiveness of mannitol compared to other ICPlowering agents.

3. To quantify the effectiveness of mannitol administration given at other stages following head injury.

\section{METHODS}

\section{Criteria for considering studies for this review}

\section{Types of studies}

Controlled trials in which subjects were assigned to treatment or control groups (placebo-controlled, no drug, different drug or different mannitol regimen) on the basis of random or quasirandom allocation. We excluded trials with a cross-over design.

\section{Types of participants}

Participants had a clinically defined acute traumatic brain injury of any severity.

\section{Types of interventions}

The treatment group received mannitol in any dose for any duration, at any time within eight weeks following injury. The control group received any of the following: mannitol in a different dose from the treatment group, another ICP-lowering agent such as barbiturates or placebo or standard care only.

\section{Types of outcome measures}

We aimed to extract from each trial the number of patients originally allocated to each group. Within each group, we aimed to extract the number of participants who died from any cause during the follow-up period or who were dead, in a vegetative state or severely disabled, compared to moderate or good recovery (according to Glasgow Coma Scale [GCS] criteria).

\section{Search methods for identification of studies}

The search was limited by date, language or publication type.

\section{Electronic searches}

The Cochrane Injuries Group Trials Search Co-ordinator searched the following:

1. Cochrane Injuries Group Specialised Register (20th April 2009);

2. CENTRAL (The Cochrane Library 2009, Issue 2);

3. MEDLINE (OvidSP) (1950 to April 2009);

4. EMBASE (OvidSP) (1980 to April 2009);

5. ISI Web of Science: Science Citation Index Expanded (SCIEXPANDED) 1970 to April 2009;

6. Conference Proceedings Citation Index-Science (CPCI-S) 1990 to April 2009;

7. PubMed (added in last 6 months; searched 21 April 2009).

Search strategies are listed in Appendix 1.

\section{Searching other resources}

The reference lists of all relevant articles identified were checked. A letter was sent to the first author of reports to ask for further information on the published report and asking them to assist in identifying any further trials which may have been conducted by them, or other investigators. Eligibility was determined by reading the reports of possible trials.

\section{Data collection and analysis}

We determined eligibility by reading the reports of possible trials and corresponding with the trialists. The reviewers independently rated quality of allocation concealment and independently extracted the data. We resolved disagreement by discussion. We calculated relative risks and 95\% confidence intervals for each trial on an intention to treat basis. For trials which used comparable treatment regimens, we planned to calculate summary relative risks and $95 \%$ confidence intervals using a fixed effects model, and to stratify the analyses on allocation concealment.

\section{RE S U L T S}

\section{Description of studies}

Four studies met the inclusion criteria.

Sayre 1996 compared the pre-hospital administration of mannitol with placebo (normal saline). Eligible patients were those with moderate and severe head injury (GCS 11 or less), above 18 years of age. Patients were excluded if they may have been pregnant, had already received a diuretic, or were receiving cardiopulmonary resuscitation. The mannitol group received $5 \mathrm{ml} /$ $\mathrm{kg}$ of $20 \%$ mannitol through a large bore IV catheter over five minutes. The placebo group was given $5 \mathrm{ml} / \mathrm{kg}$ of $0.9 \%$ saline 
solution. Forty-four participants were randomised; three were later excluded as they were found to be ineligible. The treatment to which these three patients were allocated, as well as follow-up information were unavailable. Therefore, the analysis was based upon 20 participants in the mannitol group and 21 participants in the placebo group. Length of follow-up was for two hours after arrival at the hospital.

Schwartz 1984 compared mannitol to pentobarbital. Patients with severe head injury (GCS <8), and with raised ICP for longer than 15 minutes were eligible. Treatment allocation was stratified according to the presence of intracranial haematomas. The mannitol group received $20 \%$ mannitol solution at an initial dose of $1 \mathrm{~g}$ per $\mathrm{kg}$. Additional increments were given to maintain the intracranial pressure at less than 20 torr, within a serum osmolality of mannitol of $320 \mathrm{mOs} /$ litre. The pentobarbital group received pentobarbital as an intravenous (IV) bolus of up to $10 \mathrm{mg} / \mathrm{kg}$, followed by a continuous infusion at 0.5 to $3 \mathrm{mg} / \mathrm{kg} / \mathrm{hr}$, provided that CPP remained above 50 torr. Additional increments of pentobarbital were given to maintain the intracranial pressure at less than 20 torr. For subsequent episodes of raised ICP, there was some cross-over to the alternate treatment group, but the analysis was on the original intent-to-treat. Seventy participants were randomised; 11 were later deemed ineligible and excluded. Data on the treatment to which these 11 patients were allocated and followup information were unavailable. Therefore, the analysis was based on 31 participants in the mannitol group and 28 participants in the pentobarbital group. Length of follow-up was one year.

Smith 1986 compared two regimens for guiding the administration of mannitol, one according to neurological signs and physiological measurements, and the other using ICP monitoring. Participants had a severe head injury (GCS 8 or less). The protocol for the first group used neurological signs, GCS, ventilatory values and arterial blood gas to guide administration of mannitol. In the second group, a $250 \mathrm{ml}$ bolus of mannitol (20\%) was given if ICP $>25 \mathrm{mmHg}$, and subsequent boluses were given incrementally. Eighty participants were randomised. Data were available for 40 participants in the first group, and 37 participants in the ICP-directed treatment group. Follow-up was one year.
Vialet 2003 compared mannitol to hypertonic saline. Eligible patients were those with severe head injury (GCS <8) who required intravenous infusions of an osmotic agent to treat episodes of intracranial hypertension resistant to standard therapy (cerebrospinal fluid drainage, volume expansion and/or inotropic support, hyperventilation). The mannitol group received 20\% mannitol solution. The hypertonic saline group received $7.5 \%$ hypertonic saline. The infused volume was the same for both solutions: $2 \mathrm{ml} / \mathrm{kg}$ body weight in 20 minutes. The aim was to decrease ICP to $<25 \mathrm{~mm} \mathrm{Hg}$ or to increase CPP to $>70 \mathrm{~mm} \mathrm{Hg}$. In case the first infusion failed, the patient received a second infusion within ten minutes after the end of the first infusion. Treatment failure was defined as the inability to decrease ICP to $<35 \mathrm{~mm} \mathrm{Hg}$ or to increase CPP to $>70 \mathrm{~mm} \mathrm{Hg}$ with two consecutive infusions of the selected osmotic solution. In that case, the protocol was stopped, and patients were followed up for mortality or 90-day neurologic status. Because $20 \%$ mannitol can crystallize at ambient temperature, injections could not be performed in a blinded manner. Twenty patients were randomised, ten to each group. Outcome was assessed at 90 days using the Glasgow Outcome Scale administered by a practitioner who was blind to acute patient care.

\section{Risk of bias in included studies}

Sayre 1996: The study was randomised and double-blind. Allocation concealment was by pharmacy-prepared blinded solutions.

Schwartz 1984: The study was randomised and single-blind. Allocation concealment was by using serially numbered sealed envelopes.

Smith 1986:The study was randomised but not reported as doubleblind. Allocation concealment was by the use of sealed envelopes.

Vialet 2003: The study was randomised but allocation concealment was not described. Outcome assessment was blind to acute clinical care.

The risk of bias across the four studies is summarised in Figure 1 and Figure 2. 
Figure 1. Risk of bias summary: review authors' judgements about each risk of bias item for each included study.

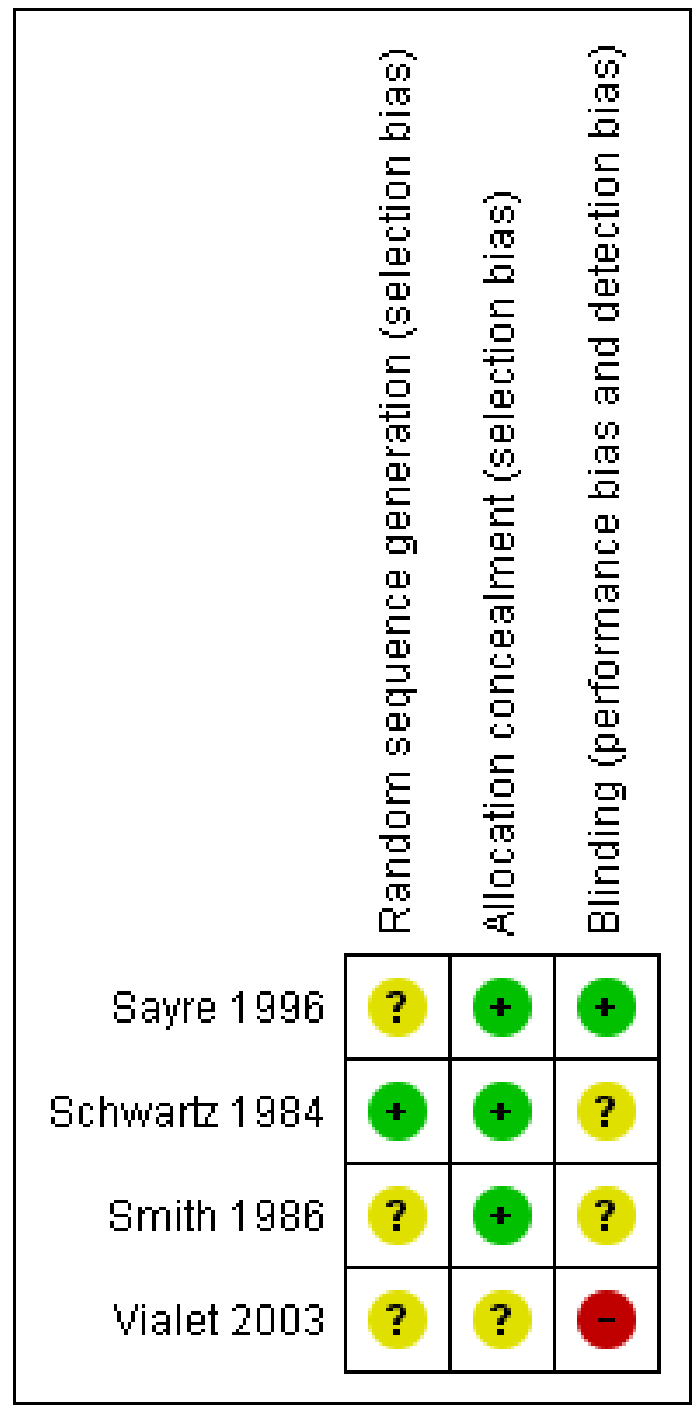

Figure 2. Risk of bias graph: review authors' judgements about each risk of bias item presented as percentages across all included studies. Four studies are included in this review.

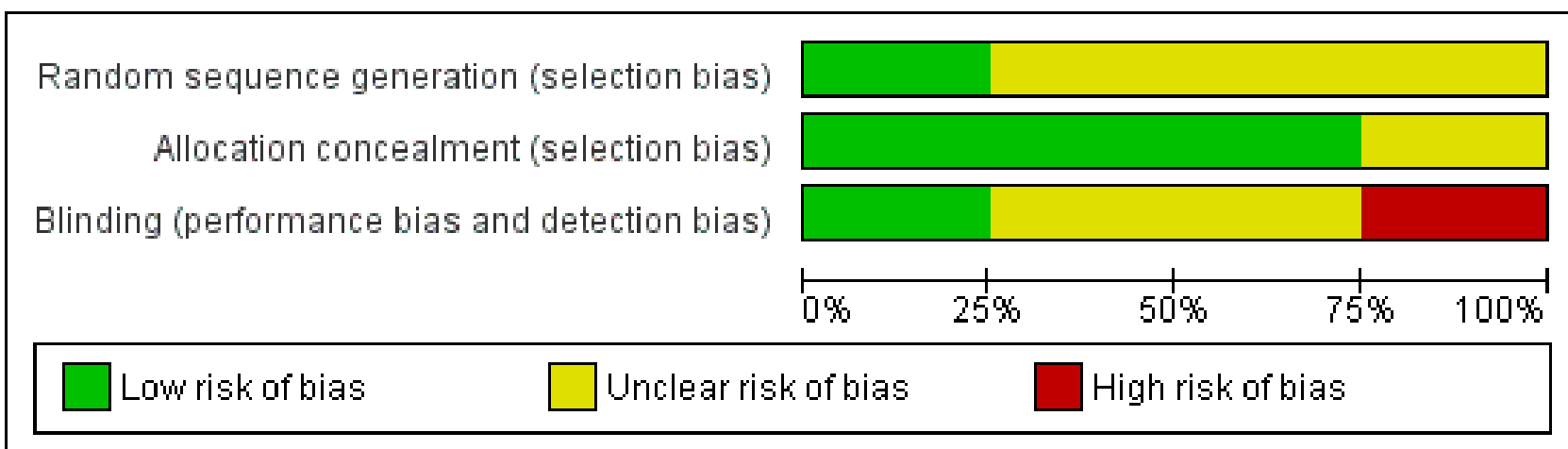

\section{Effects of interventions}

One trial compared ICP-directed therapy to 'standard care' in which mannitol therapy was directed by neurological signs (Smith 1986).
The study was randomised and allocation concealment was by the use of sealed envelopes. For ICP-directed treatment compared to treatment based on neurological signs, the RR for death was 0.83 
(95\% $\mathrm{Cl} 0.47$ to 1.46); this trial demonstrated a similar effect for death or severe disability ( $\mathrm{RR}=0.88 ; 95 \% \mathrm{Cl} 0.55$ to 1.38$)$.

One trial compared mannitol to pentobarbital (Schwartz 1984). This trial was randomised and single blind. Only patients with known raised ICP were included. For mannitol compared to pentobarbital in the treatment of patients with raised ICP, the RR for death was 0.85 (95\% $\mathrm{Cl} 0.52$ to 1.38$)$.

One trial compared mannitol to hypertonic saline (Vialet 2003). This trial was randomised and single blind. Only patients with head injury and persistent coma who required osmotherapy to treat episodes of intracranial hypertension resistant to standard therapy were included. For mannitol compared to hypertonic saline in the treatment of refractory intracranial hypertension episodes in comatose patients with severe head injury, the RR for death was 1.25 (95\% $\mathrm{Cl} 0.47$ to 3.33 ).

The effectiveness of pre-hospital administration of mannitol against placebo was investigated in Sayre 1996. This study was randomised and allocation concealment was through pharmacy prepared blinded solutions. For pre-hospital infusion of mannitol compared to placebo in patients with head injury and multiple trauma, the RR for death was $1.75(95 \% \mathrm{Cl} 0.48$ to 6.38$)$.

\section{DISCUSSION}

There were few eligible trials of mannitol therapy in head-injured patients.

ICP-directed treatment showed a small beneficial effect on mortality when compared to treatment directed according to neurological signs and physiological indicators $(\mathrm{RR}=0.83 ; 95 \% \mathrm{Cl}$ 0.47 to 1.46). The method of allocation concealment in this study was adequate to prevent foreknowledge of treatment, and was unlikely to have led to bias. Owing to small patient numbers, the effect measure is imprecise. It must be noted that in this study the ICP-directed protocol initiated mannitol only when the ICP rose to above $25 \mathrm{mmHg}$. Therefore these results cannot be extrapolated to
ICP-directed protocols which initiate mannitol therapy at a lower level.

Mannitol therapy may have a beneficial effect on mortality when compared to pentobarbital therapy. However, the single trial which tested this (Schwartz 1984) yielded an imprecise effect measure, which also may be compatible with no difference, or a beneficial effect of pentobarbital. The trial was testing an initial treatment of mannitol compared to pentobarbital as some patients later received the alternate therapy if the allocated therapy failed to control ICP.

Mannitol therapy may have a detrimental effect on mortality when compared to hypertonic saline therapy. The single trial which compared mannitol to hypertonic saline (Vialet 2003) was too small for reliable conclusions. The trial was not designed to test the effect of these osmotic agents on neurologic recovery or death.

The single trial which compared pre-hospital administration of mannitol to placebo showed an increase in mortality amongst the mannitol-treated patients ( $\mathrm{RR}=1.75 ; 95 \% \mathrm{Cl} 0.48$ to 6.38). The estimate yielded by this trial is imprecise owing to the small sample size. The effect measure also may be compatible with no difference, or a beneficial effect of pre-hospital administration of mannitol.

\section{AUTHORS' CONCLUSIONS}

\section{Implications for practice}

There is insufficient reliable evidence to make recommendations on the use of mannitol in the management of patients with traumatic brain injury.

\section{Implications for research}

There are many unanswered questions regarding the optimal use of mannitol following acute traumatic head injury. The widespread current use of mannitol, and lack of clarity regarding optimal administration, present an ideal opportunity for the conduct of randomised controlled trials. 


\section{RE F E R E N C E S}

\section{References to studies included in this review}

\section{Sayre 1996 \{published data only\}}

Sayre MR, Daily SW, Stern SA, Storer DL, van Loveren HR, Hurst JD. Out-of-hospital administration of mannitol does not change systolic blood pressure. Academic Emergency Medicine 1996;3(9):840-8. [MEDLINE: 1997024527]

\section{Schwartz 1984 \{published data only\}}

Schwartz ML, Tator CH, Rowed DW, Reid SR, Meguro K, Andrews DF. The University of Toronto head injury treatment study: a prospective, randomized comparison of pentobarbital and mannitol. Canadian Journal of Neurological Sciences 1984;11(4):434-40. [MEDLINE: 1985098889]

\section{Smith 1986 \{published data only\}}

Smith HP, Kelly DL Jr, McWhorter JM, Armstrong D, Johnson R, Transou C, et al. Comparison of mannitol regimens in patients with severe head injury undergoing intracranial monitoring. Journal of Neurosurgery 1986;65(6):820-4. [MEDLINE: 1987035848]

\section{Vialet 2003 \{published data only\}}

Vialet R, Albanese J, Thomachot L, Antonini F, Bourgouin A, Alliez $B$, et al. Isovolume hypertonic solutes (sodium chloride or mannitol) in the treatment of refractory posttraumatic intracranial hypertension: $2 \mathrm{~mL} / \mathrm{kg} 7.5 \%$ saline is more effective than $2 \mathrm{~mL} / \mathrm{kg} 20 \%$ mannitol. Critical Care Medicine 2003;31(6):1683-7. [MEDLINE: 12794404]

\section{References to studies excluded from this review}

\section{Battison 2005 \{published data only\}}

Battison C, Andrews PJ, Graham C, Petty T. Randomized, controlled trial of the effect of a $20 \%$ mannitol solution and a $7.5 \%$ saline $/ 6 \%$ dextran solution on increased intracranial pressure after brain injury. Critical Care Medicine 2005;33(1):196-202. [MEDLINE: 15644669]

\section{Cruz 2001 \{published data only\}}

Cruz C, Minoja G, Okuchi K. Improving clinical outcomes from acute subdural hematomas with emergency preoperative administration of high doses of mannitol: a randomized trial. Neurosurgery 2001;49(4):864-71.

\section{Cruz 2002 \{published data only\}}

Cruz C, Minoja G, Okuchi K. Major clinical and physiological benefits of early high doses of mannitol for intraparenchymal temporal lobe hemorrhages with abnormal pupilary widening. Neurosurgery 2002;51(3):628-38.

\section{Cruz 2004 \{published data only\}}

Cruz J, Minoja G, Okuchi K, Facco E. Successful use of the new high-dose mannitol treatment in patients with Glasgow Coma Scores of 3 and bilateral abnormal pupillary widening: a randomized trial. Journal of Neurosurgery 2004;100(3):376-83. [MEDLINE: 15035271]
Fortune 1995 \{published data only\}

Fortune JB, Feustel PJ, Graca I, Hasselbarth J, Kuehler DH. Effect of hyperventilation, mannitol, and ventriculostomy drainage on cerebral blood-flow after head-injury. Journal of Trauma-Injury Infection and Critical Care 1995;39(6):1091-9.

\section{Francony 2008 \{published data only\}}

Francony $\mathrm{G}$, Fauvage B, Falcon D, Canet C, Dilou H, Lavagne $\mathrm{P}$, et al. Equimolar doses of mannitol and hypertonic saline in the treatment of increased intracranial pressure. Critical Care Medicine 2008;36(3):795-800.

Gaab 1989 \{published data only\}

Gaab MR, Seegers K, Goetz C. THAM (Tromethamine, "TrisBuffer"): Effective therapy of traumatic brain swelling?. In: Hoff JT, Betz AL editor(s). Intracranial Pressure VII. Berlin Heidelberg: Springer-Verlag, 1989:616-9.

\section{Harutjunyan 2005 \{published data only\}}

Harutjunyan L, Holz C, Rieger A, Menzel M, Grond S, Soukup J. Efficiency of $7.2 \%$ hypertonic saline hydroxyethyl starch 200/0.5 versus mannitol $15 \%$ in the treatment of increased intracranial pressure in neurosurgical patients - a randomized clinical trial. Critical Care 2005;9:R530-R540.

Ichai 2009 \{published data only\}

Ichai C, Armando G, Orban J-C, Berthier F, Rami L, SamatLong $\mathrm{C}$, et al. Sodium lactate versus mannitol in the treatment of intracranial hypertensive episodes in severe traumatic braininjured patients. Intensive Care Medicine 2009;35:471-479.

Levin 1979 \{published data only\}

Levin AB, Duff TA, Javid MJ. Treatment of increased intracranial pressure: a comparison of different hyperosmotic agents and the use of thiopental. Neurosurgery 1979;5(5):570-5.

Midgely 1993 \{published data only\}

Midgley S. CPP and SJO2 with ICP Reduction Therapy After Severe Head Injury. Intracranial Pressure. New York: SpringerVerlag, 1993:558-63.

Smedema 1993 \{published data only\}

Smedema RJA. Comparison Study Between Mannitol and Glycerol Therapy in Reducing Intracranial Pressure. Intracranial Pressure. Vol. 8, New York: Springer-Verlag, 1993:605-8.

\section{Additional references}

\section{Ghajar 1995}

Ghajar J, Hariri RJ, Narayan RK, et al. Survey of critical care management of comatose, head-injured patients in the United States. Critical Care Medicine 1995;23(3):560-7.

\section{Jeevaratnam 1996}

Jeevaratnam DR, Menon DK. Survey of intensive care of severely head injured patients in the United Kingdom. BMJ 1996;312:994-7. 


\section{Matta 1996}

Matta B, Menon D. Severe head injury in the United Kingdom and Ireland: a survey of practice and implications for management. Critical Care Medicine 1996; 24;10:1743-8.

\section{CHARACTERISTICS OF STUDIES}

Characteristics of included studies [ordered by study ID]

\section{Task Force 1995}

Task force of the American Association of Neurological Surgeons and Joint Section in Neurotrauma and Critical Care. Guidelines for the management of severe head injury. Brain Trauma Foundation, 1995.

Sayre 1996

\begin{tabular}{ll}
\hline Methods & Randomised and double blind placebo controlled trial. \\
\hline Participants & Moderate and severe head injury (CGS 11 and less), above 18 years of age. \\
\hline Interventions & $\begin{array}{l}\text { Mannitol received } 5 \mathrm{ml} / \mathrm{kg} \text { of } 20 \% \text { mannitol through large-bore intravenous catheter over five minutes; } \\
\text { placebo group were given } 5 \mathrm{ml} / \mathrm{kg} \text { of } 0.9 \% \text { saline solution. }\end{array}$ \\
\hline Outcomes & Death was reported. Length of follow-up was two hours after hospital admission. \\
\hline Notes & Testing pre-hospital administration of mannitol. \\
\hline
\end{tabular}

\section{Risk of bias}

\begin{tabular}{lll}
\hline Bias & Authors' judgement & Support for judgement \\
\hline $\begin{array}{l}\text { Random sequence genera- } \\
\text { tion (selection bias) }\end{array}$ & Unclear risk & Information not provided in published study. \\
\hline $\begin{array}{l}\text { Allocation concealment } \\
\text { (selection bias) }\end{array}$ & Low risk & $\begin{array}{l}\text { Quote: "The study solutions were prepared by the pharmacy department and } \\
\text { were identified by a code number. An envelope showing the code number } \\
\text { identified the contents of that IV bag. If the treating physicians at the receiving } \\
\text { trauma center believed it was necessary to know whether the patient had re- } \\
\text { ceived mannitol or placebo, the envelope could be opened". }\end{array}$ \\
\hline
\end{tabular}

Blinding (performance Low risk bias and detection bias) All outcomes
Comment: Blinding is implied but not explicitly stated.

Quote: "This was a prospective, randomized, double-blind, placebo-controlled clinical trial of the effect of mannitol on systolic BP in multiply injured patients with severe head injuries".

Quote: "The study solutions were prepared by the pharmacy department and were identified by a code number. An envelope showing the code number identified the contents of that IV bag. If the treating physicians at the receiving trauma center believed it was necessary to know whether the patient had received mannitol or placebo, the envelope could be opened".

Quote: "At the conclusion of the 2-hour monitoring period, the EM resident and the investigator recording the patient data were asked to provide their guesses as to whether mannitol or placebo had been administered to the patient. For those patients actually given mannitol, the resident correctly picked mannitol in 11 of 13 cases for which a guess was given; and the investigators correctly picked mannitol in 13 of 14 cases. For those patients actually given placebo, the resident correctly picked placebo in 5 of 10 cases for which a guess was given; and the investigators correctly picked placebo for 13 of 16 cases". 
Schwartz 1984

\begin{tabular}{ll}
\hline Methods & Randomised single blind trial. \\
\hline Participants & $\begin{array}{l}\text { Severe head injury (GCS<8). Participants had to have already been resuscitated and had raised ICP for } \\
\text { more than } 15 \text { minutes. }\end{array}$ \\
\hline Interventions & $\begin{array}{l}\text { The mannitol group received } 20 \% \text { mannitol solution at an initial dose of } 1 \mathrm{~g} \mathrm{per} \mathrm{kg} . \text { Additional incre- } \\
\text { ments were given to maintain the intracranial pressure at less than } 20 \text { torr, within a serum osmolarity } \\
\text { of mannitol of } 320 \mathrm{mOs} / \mathrm{L} .\end{array}$ \\
& $\begin{array}{l}\text { The pentobarbital group received pentobarbital as an IV bolus of up to } 10 \mathrm{mg} / \mathrm{kg}, \text { followed by a contin- } \\
\text { uous infusion at } 0.5-3 \mathrm{mg} / \mathrm{kg} / \mathrm{hr}, \text { provided that CPP remained above } 50 \text { torr, Additional increments of } \\
\text { pentobarbital were given to maintain the intracranial pressure at less than } 20 \text { torr. }\end{array}$
\end{tabular}

Outcomes Death reported. Follow-up to three months.

\section{Risk of bias}

\begin{tabular}{lll}
\hline Bias & Authors' judgement & Support for judgement \\
\hline $\begin{array}{l}\text { Random sequence genera- } \\
\text { tion (selection bias) }\end{array}$ & Low risk & Quote: "The starting drug was determined by a random number generator." \\
\hline $\begin{array}{l}\text { Allocation concealment } \\
\text { (selection bias) }\end{array}$ & Low risk & $\begin{array}{l}\text { Quote: "The mechanism of randomization was the opening of a serially-num- } \\
\text { bered, sealed envelope taken from one of two packages of envelopes, one for } \\
\text { patients who had had intracranial hematomas removed and one for those who } \\
\text { developed raised intracranial pressure from brain injury alone." }\end{array}$ \\
\hline $\begin{array}{l}\text { Blinding (performance } \\
\text { bias and detection bias) } \\
\text { All outcomes }\end{array}$ & Unclear risk & . \\
\hline
\end{tabular}

\section{Smith 1986}

\begin{tabular}{ll}
\hline Methods & Randomised controlled trial; not reported as double-blind. \\
\hline Participants & Severe head injury (GCS 8 or less). \\
\hline Interventions & $\begin{array}{l}\text { Compared two regimens of guiding the administration of mannitol, one according to neurological signs } \\
\text { and physiological measurements, and the other using ICP monitoring. The protocol for the first group } \\
\text { used neurological signs, GCS, ventilatory values and arterial blood gas to guide administration. In the } \\
\text { second group, a } 250 \mathrm{ml} \text { bolus of mannitol (20\%) was given if ICP }>25 \mathrm{mmHg} \text {, and subsequent boluses } \\
\text { were given incrementally. }\end{array}$
\end{tabular}

Outcomes Deaths and neurological disability were reported. Follow-up was one year.

\section{Notes}

\section{Risk of bias}

\begin{tabular}{lll}
\hline Bias & Authors' judgement & Support for judgement \\
\hline $\begin{array}{l}\text { Random sequence genera- } \\
\text { tion (selection bias) }\end{array}$ & Unclear risk & No information provided in published study
\end{tabular}


Smith 1986 (Continued)

$\begin{array}{ll}\begin{array}{l}\text { Allocation concealment } \\ \text { (selection bias) }\end{array} & \text { Quote: "The patients were randomly assigned to one of two groups by means } \\ & \text { of sealed envelopes containing cards designating the assigned protocol: Group } \\ \text { I (mannitol therapy based on ICP monitoring) or Group II (empirical mannitol } \\ \text { therapy)". }\end{array}$

Blinding (performance

Unclear risk

No information provided in published study.

bias and detection bias)

All outcomes

Vialet 2003

\begin{tabular}{ll}
\hline Methods & Randomised single blind trial. \\
\hline Participants & $\begin{array}{l}\text { Severe head injury (GCS<8) who required intravenous infusions of an osmotic agent to treat episodes of } \\
\text { intracranial hypertension resistant to standard therapy. }\end{array}$ \\
\hline Interventions & $\begin{array}{l}\text { Compared two osmotic agents, mannitol and hypertonic saline solution. The mannitol group received } \\
20 \% \text { mannitol solution. The hypertonic saline group received } 7.5 \% \text { hypertonic saline. The infused vol- } \\
\text { ume was the same for both solutions: } 2 \mathrm{ml} / \mathrm{kg} \text { body weight in } 20 \text { minutes. }\end{array}$ \\
\hline Outcomes & Death and neurological disability reported. Follow-up to three months. \\
\hline Notes &
\end{tabular}

\section{Risk of bias}

\begin{tabular}{lll}
\hline Bias & Authors' judgement & Support for judgement \\
\hline $\begin{array}{l}\text { Random sequence genera- } \\
\text { tion (selection bias) }\end{array}$ & Unclear risk & No information provided in published study. \\
\hline $\begin{array}{l}\text { Allocation concealment } \\
\text { (selection bias) }\end{array}$ & Unclear risk & $\begin{array}{l}\text { Quote: "After randomization, the patients received either 20\% mannitol (1160 } \\
\text { mOsm } / \mathrm{kg} / \mathrm{H} 2 \mathrm{O}) \text { or } 7.5 \% \mathrm{HSS}(2400 \mathrm{mOsm} / \mathrm{kg} / \mathrm{H} 2 \mathrm{O}) " .\end{array}$ \\
\hline $\begin{array}{l}\text { Blinding (performance } \\
\text { bias and detection bias) } \\
\text { All outcomes }\end{array}$ & High risk & $\begin{array}{l}\text { Quote: "Because } 20 \% \text { mannitol can crystallize at ambient temperature, injec- } \\
\text { tions could not be performed in a blinded manner." }\end{array}$ \\
\hline
\end{tabular}

Characteristics of excluded studies [ordered by study ID]

\begin{tabular}{ll}
\hline Study & Reason for exclusion \\
\hline Battison 2005 & Cross-over design. \\
\hline Cruz 2001 & $\begin{array}{l}\text { Concerns about the integrity of the trial data. Manuscripts does not indicate where the patients } \\
\text { were randomised and despite an investigation by the Cochrane Injuries Group this remains open to } \\
\text { question. }\end{array}$ \\
\hline Cruz 2002 & $\begin{array}{l}\text { Concerns about the integrity of the trial data. Manuscripts does not indicate where the patients } \\
\text { were randomised and despite an investigation by the Cochrane Injuries Group this remains open to } \\
\text { question. }\end{array}$ \\
\hline
\end{tabular}




\begin{tabular}{ll}
\hline Study & Reason for exclusion \\
\hline Cruz 2004 & $\begin{array}{l}\text { Concerns about the integrity of the trial data. Manuscripts does not indicate where the patients } \\
\text { were randomised and despite an investigation by the Cochrane Injuries Group this remains open to } \\
\text { question. }\end{array}$ \\
\hline Fortune 1995 & Controlled follow up study; no means to reduce bias in the selection of the control group was used. \\
\hline Francony 2008 & Participants were not all head-injured patients. \\
\hline Gaab 1989 & Randomised to a diuretic, not necessarily mannitol. \\
\hline Harutjunyan 2005 & Participants were not all head-injured patients. \\
\hline Ichai 2009 & Cross-over design. \\
\hline Levin 1979 & Participants were not all head injured; had a cross-over design. \\
\hline Midgely 1993 & Cross-over design. \\
\hline Smedema 1993 & Participants were not all head-injured patients. \\
\hline
\end{tabular}

DATA AND ANALYSES

Comparison 1. ICP-directed mannitol ('treatment') compared to mannitol according to neurological signs ('control')

\begin{tabular}{lllll}
\hline Outcome or subgroup title & $\begin{array}{l}\text { No. of } \\
\text { studies }\end{array}$ & $\begin{array}{l}\text { No. of } \\
\text { partici- } \\
\text { pants }\end{array}$ & Statistical method & Effect size \\
\hline 1 Death & 1 & Risk Ratio (M-H, Fixed, 95\% Cl) & Subtotals only \\
\hline 2 Death or severe disability & 1 & Risk Ratio (M-H, Fixed, 95\% Cl) & Subtotals only \\
\hline
\end{tabular}

Analysis 1.1. Comparison 1 ICP-directed mannitol ('treatment') compared to mannitol according to neurological signs ('control'), Outcome 1 Death.

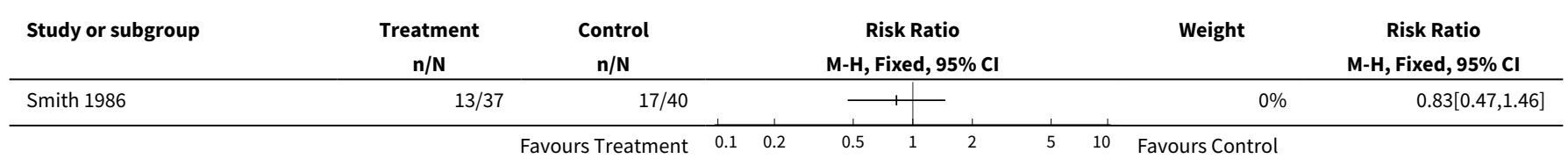


Analysis 1.2. Comparison 1 ICP-directed mannitol ('treatment') compared to mannitol according to neurological signs ('control'), Outcome 2 Death or severe disability.

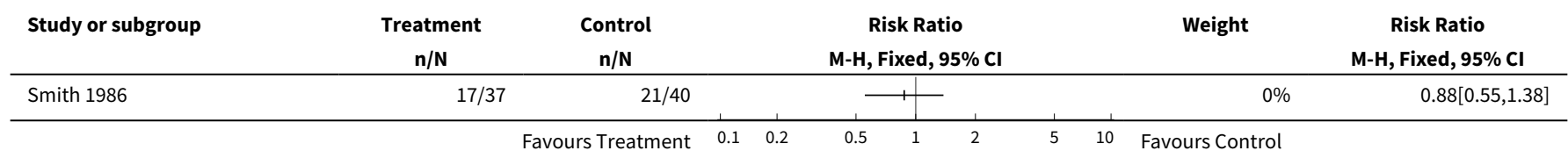

\section{Comparison 2. Mannitol versus pentobarbital}

\begin{tabular}{lllll}
\hline Outcome or subgroup title & $\begin{array}{l}\text { No. of } \\
\text { studies }\end{array}$ & $\begin{array}{l}\text { No. of partici- } \\
\text { pants }\end{array}$ & Statistical method & Effect size \\
\hline 1 Death & 1 & Risk Ratio (M-H, Fixed, $95 \% \mathrm{Cl})$ & Subtotals only \\
\hline
\end{tabular}

Analysis 2.1. Comparison 2 Mannitol versus pentobarbital, Outcome 1 Death.

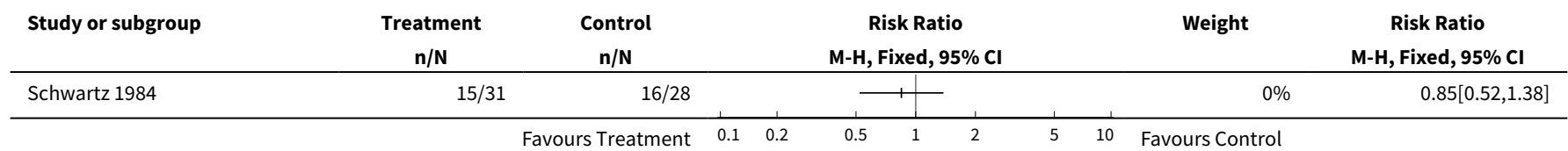

Comparison 3. Mannitol versus hypertonic saline

\begin{tabular}{lllll}
\hline Outcome or subgroup title & $\begin{array}{l}\text { No. of } \\
\text { studies }\end{array}$ & $\begin{array}{l}\text { No. of partici- } \\
\text { pants }\end{array}$ & Statistical method & Effect size \\
\hline 1 Death & 1 & Risk Ratio (M-H, Fixed, 95\% Cl) & Subtotals only \\
\hline
\end{tabular}

Analysis 3.1. Comparison 3 Mannitol versus hypertonic saline, Outcome 1 Death.

\begin{tabular}{|c|c|c|c|c|c|}
\hline Study or subgroup & $\begin{array}{c}\text { Treatment } \\
n / N\end{array}$ & $\begin{array}{l}\text { Control } \\
n / N\end{array}$ & $\begin{array}{c}\text { Risk Ratio } \\
\text { M-H, Fixed, } 95 \% \text { Cl }\end{array}$ & Weight & $\begin{array}{c}\text { Risk Ratio } \\
\text { M-H, Fixed, } 95 \% \mathrm{Cl}\end{array}$ \\
\hline Vialet 2003 & $5 / 10$ & $4 / 10$ & \begin{tabular}{l|l} 
& 1 \\
\end{tabular} & $0 \%$ & $1.25[0.47,3.33]$ \\
\hline
\end{tabular}

Comparison 4. Mannitol versus placebo

\begin{tabular}{lllll}
\hline Outcome or subgroup title & $\begin{array}{l}\text { No. of } \\
\text { studies }\end{array}$ & $\begin{array}{l}\text { No. of partici- } \\
\text { pants }\end{array}$ & Statistical method & Effect size \\
\hline 1 Death & 1 & Risk Ratio (M-H, Fixed, $95 \% \mathrm{Cl})$ & Subtotals only \\
\hline
\end{tabular}


Analysis 4.1. Comparison 4 Mannitol versus placebo, Outcome 1 Death.

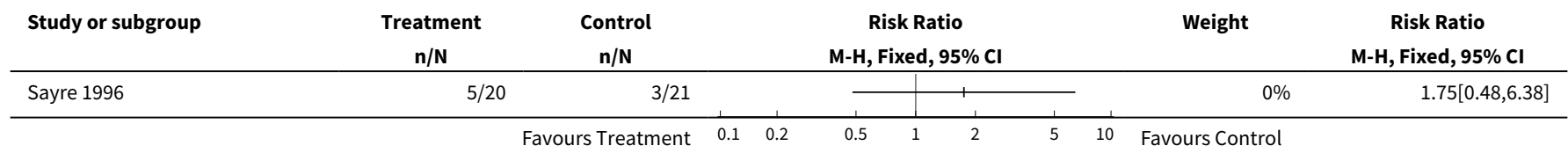

\section{APPEN DICES}

\section{Appendix 1. Search strategies}

\section{Cochrane Injuries Group's Specialised Register}

(mannitol or Mannit or Mannite or Osmosal or Osmosteril or Resectisol or Aridol or Bronchitol or bromine or mitobronitol or dibromomannitol or myelobromol or nsc- $94^{\star}$ or osmitrol or osmofundin or "(l)-mannitol" or "Dextro Mannitol" or D-Mannitol or (diuretic* and osmotic )) AND ("intracranial pressure" OR "intracranial hypotension" OR "intracranial hypertension" or head" or brain*)

\section{CENTRAL (The Cochrane Library)}

\#1MeSH descriptor Craniocerebral Trauma explode all trees

\#2MeSH descriptor Cerebrovascular Trauma explode all trees \#3MeSH descriptor Brain Edema explode all trees

\#4(brain or cerebral or intracranial) next (oedema or edema or swell ${ }^{\star}$ )

\#5MeSH descriptor Glasgow Coma Scale explode all trees

\#6MeSH descriptor Glasgow Outcome Scale explode all trees

\#7MeSH descriptor Unconsciousness explode all trees

\#8glasgow next (coma or outcome) next (score or scale)

\#9(Unconscious ${ }^{\star}$ or coma* or concuss* or 'persistent vegetative state') near5 (injur ${ }^{\star}$ or trauma* or damag ${ }^{\star}$ or wound ${ }^{\star}$ or fracture ${ }^{\star}$ )

\#10"Rancho Los Amigos Scale"

\#11(head or crani* or cerebr* or capitis or brain* or forebrain ${ }^{\star}$ or skull ${ }^{\star}$ or hemispher ${ }^{\star}$ or intra-cran ${ }^{\star}$ or inter-cran ${ }^{\star}$ ) near3 (injur ${ }^{\star}$ or trauma* or damag* or wound* or fracture* or contusion*)

\#12Diffuse next axonal next injur*

\#13(head or crani* or cerebr* or brain* or intra-cran* or inter-cran*) near3 (haematoma* or hematoma* or haemorrhag* or hemorrhag* or bleed* or pressure)

\#14(\#1 OR \#2 OR \#3 OR \#4 OR \#5 OR \#6 OR \#7 OR \#8 OR \#9 OR \#10 OR \#11 OR \#12 OR \#13)

$\# 15 \mathrm{MeSH}$ descriptor Mannitol explode all trees

\#16MeSH descriptor Diuretics, Osmotic explode all trees

\#17(mannitol or Mannit or Mannite or Osmosal or Osmosteril or Resectisol or Aridol or Bronchitol or bromine or mitobronitol or dibromomannitol or myelobromol or nsc-94* or osmitrol or osmofundin or "(l)-mannitol" or Dextro Mannitol or D-Mannitol or (diuretic* $\operatorname{adj} 5$ osmotic $\left.\left.{ }^{\star}\right)\right)$.ab,ti.

\#18(\#15 OR \#16 OR \#17)

\#19 (\#14 and \#18)

\section{MEDLINE (OvidSP)}

1.exp mannitol/

2.exp Diuretics, Osmotic/

3. (mannitol or Mannit or Mannite or Osmosal or Osmosteril or Resectisol or Aridol or Bronchitol or bromine or mitobronitol or dibromomannitol or myelobromol or nsc-94* or osmitrol or osmofundin or "(l)-mannitol" or Dextro Mannitol or D-Mannitol or (diuretic* adj5 osmotic*)).ab,ti.

4.1 or 2 or 3

5.exp Craniocerebral Trauma/

6.exp Brain Edema/

7.exp Glasgow Coma Scale/

8.exp Glasgow Outcome Scale/

9.exp Unconsciousness/

10.exp Cerebrovascular Trauma/ 
11.((head or crani* or cerebr* or capitis or brain* or forebrain* or skull* or hemispher* or intra-cran* or inter-cran*) adj5 (injur* or trauma* or damag* or wound ${ }^{\star}$ or fracture* or contusion*)).ab,ti.

12.((head or crani* or cerebr* or brain ${ }^{\star}$ or intra-cran* or inter-cran $\left.{ }^{\star}\right)$ adj5 (haematoma* or hematoma* or haemorrhag* or hemorrhag* or bleed $^{\star}$ or pressure)).ti,ab.

13. (Glasgow adj (coma or outcome) adj (scale* or score*)).ab,ti.

14."rancho los amigos scale".ti,ab.

15.("diffuse axonal injury" or "diffuse axonal injuries").ti,ab.

16.((brain or cerebral or intracranial) adj3 (oedema or edema or swell $\left.\left.{ }^{\star}\right)\right)$.ab,ti.

17.((unconscious ${ }^{\star}$ or coma* ${ }^{\star}$ r concuss ${ }^{\star}$ or 'persistent vegetative state') adj3 (injur ${ }^{\star}$ or trauma* or damag* or wound ${ }^{\star}$ or fracture $)$ ).ti,ab.

18.exp coma/

19.or/5-18

20.4 and 19

21.randomi?ed.ab,ti.

22.randomized controlled trial.pt.

23.controlled clinical trial.pt.

24.placebo.ab.

25.clinical trials as topic.sh.

26.randomly.ab.

27.trial.ti.

28.21 or 22 or 23 or 24 or 25 or 26 or 27

29.(animals not (humans and animals)).sh.

30.28 not 29

31.30 and 20

\section{EMBASE (OvidSP)}

1.exp mannitol/

2.exp Osmotic Diuretic Agent/

3. (mannitol or Mannit or Mannite or Osmosal or Osmosteril or Resectisol or Aridol or Bronchitol or bromine or mitobronitol or dibromomannitol or myelobromol or nsc-94* or osmitrol or osmofundin or "(l)-mannitol" or Dextro Mannitol or D-Mannitol or (diuretic* $\operatorname{adj} 5$ osmotic $\left.)^{\star}\right) \cdot$ ab,ti.

4.1 or 2 or 3

5.exp Brain Injury/

6.exp Brain Edema/

7.exp Glasgow Coma Scale/

8.exp Glasgow Outcome Scale/

9.exp Rancho Los Amigos Scale/

10.exp Unconsciousness/

11.((brain or cerebral or intracranial) adj5 (oedema or edema or swell $\left.\left.{ }^{\star}\right)\right)$.ab,ti.

12.((head or crani* ${ }^{\star}$ or cerebr ${ }^{\star}$ or capitis or brain* or forebrain* or skull* or hemispher* or intra-cran* or inter-cran $\left.{ }^{\star}\right)$ adj5 (injur ${ }^{\star}$ or trauma* or damag* or wound ${ }^{\star}$ or fracture* or contusion*)).ab,ti.

13.(Glasgow adj (coma or outcome) adj (scale* or score $\left.{ }^{\star}\right)$ ).ab,ti.

14. Rancho Los Amigos Scale.ab,ti.

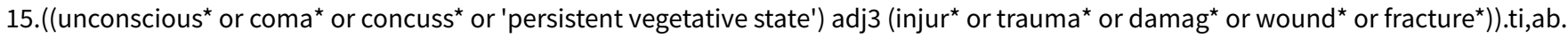
16.Diffuse axonal injur*ab,ti.

17.((head or crani* or cerebr ${ }^{\star}$ or brain* or intra-cran* or inter-cran*) adj3 (haematoma* or hematoma* or haemorrhag* or hemorrhag* or bleed $^{\star}$ or pressure)).ab,ti.

18.or/5-17

19.exp Randomized Controlled Trial/

20.exp controlled clinical trial/

21.randomi?ed.ab,ti.

22.placebo.ab.

23. ${ }^{\star}$ Clinical Trial/

24.randomly.ab.

25.trial.ti.

26.19 or 20 or 21 or 22 or 23 or 24 or 25

27.exp animal/ not (exp human/ and exp animal/)

28.26 not 27

29.28 and 18

30.4 and 29

ISI Web of Science: Science Citation Index Expanded (SCI-EXPANDED) \& Conference Proceedings Citation Index- Science (CPCI-S) 
1.Topic=(mannitol or Mannit or Mannite or Osmosal or Osmosteril or Resectisol or Aridol or Bronchitol or bromine or mitobronitol or dibromomannitol or myelobromol) OR Topic=(nsc-94* or osmitrol or osmofundin or "(l)-mannitol" or "Dextro Mannitol" or D-Mannitol or (diuretic* and osmotic $\left.{ }^{\star}\right)$ )

2.Topic=(intracranial pressure OR intracranial hypotension OR intracranial hypertension or head ${ }^{\star}$ or brain ${ }^{\star}$ )

3.TS=(clinical OR control* OR placebo OR random OR randomised OR randomized OR randomly OR random order OR random sequence OR random allocation OR randomly allocated OR at random) SAME TS=(trial* or group ${ }^{\star}$ or study or studies or placebo or controlled)

4.1 and 2 and 3

\section{PubMed}

1.(Mannitol OR Mannit OR Mannite OR Osmosal OR Osmosteril OR Resectisol OR Aridol OR Bronchitol OR Bromine OR Mitobronitol OR Dibromomannitol OR Myelobromol OR Nsc-94* OR Osmitrol OR Osmofundin OR "(l)-mannitol" OR "Dextro Mannitol" OR D-Mannitol OR (diuretic* and osmotic $\left.{ }^{\star}\right)$ )

2.("intracranial pressure" OR "intracranial hypotension" OR "intracranial hypertension" OR head OR brain)

3.((randomized controlled trial[pt] OR controlled clinical trial[pt]) OR (randomized OR randomised OR randomly OR placebo[tiab]) OR (trial[ti]) OR ("Clinical Trials as Topic"[MeSH Major Topic])) NOT (("Animals"[Mesh]) NOT ("Humans"[Mesh] AND "Animals"[Mesh]))

4.\#1 AND \#2 AND \#3

\section{FEE D B A C K}

\section{Mannitol for acute traumatic brain injury}

\section{Summary}

A. The search strategy would be clearer if the reviewer specified what additional search terms were used within the Injuries Group database to identify relevant articles (e.g., mannitol And acute brain injury). Also, the report does not specify whether any other databases, such as Medline or Embase, were searched, and if so, what search terms were used. The search should specify the total number of reports that were identified by the search strategy.

B. Would it be correct to interpret the review as demonstrating that there is no good evidence (i.e. no RCT's comparing mannitol to placebo or alternate therapies) to support our current mannitol use post-head injury? Presumably current use of mannitol by clinicians is based primarily on the pharmacological activities of mannitol, observational human studies, and animal evidence supporting its potential benefit.

\section{Reply}

A. We did not use any additional search terms in the Injuries Group database apart from 'mannitol'. No other databases, such as EMBASE, were searched separately (these searches were already included in the Injuries Group database).

B. Yes - the review concludes that there is a lack of evidence for effectiveness, which is not the same as saying there is evidence of a lack of effectiveness.

\section{Contributors}

Dr Michael Bullard

WHAT'S NEW

\begin{tabular}{lll}
\hline Date & Event & Description \\
\hline 6 August 2013 & Amended & Copy edits made to the text. \\
\hline
\end{tabular}

\section{H ISTORY}

Protocol first published: Issue 1, 1998

Review first published: Issue 1, 1998

\begin{tabular}{lll}
\hline Date & Event & Description \\
\hline 20 April 2009 & New search has been performed & The search has been updated to April 2009. \\
\hline
\end{tabular}




\begin{tabular}{lll}
\hline Date & Event & Description \\
\hline 20 April 2009 & $\begin{array}{l}\text { New citation required but conclusions } \\
\text { have not changed }\end{array}$ & $\begin{array}{l}\text { The search has been updated to April 2009. No new trials were } \\
\text { identified. The conclusions remain the same. }\end{array}$ \\
\hline 10 July 2008 & Amended & Converted to new review format. \\
\hline 22 November 2006 & Amended & $\begin{array}{l}\text { November } 2006 \\
\text { In response to concerns raised about the integrity of the data } \\
\text { from the trials by Cruz et al, the Cochrane Injuries Group under- } \\
\text { took an investigation in which attempts were made to find out } \\
\text { where the patients were recruited and to access the original tri- } \\
\text { al data for external validation. Despite considerable efforts the } \\
\text { Group is unable to provide any reassurance about the integrity of } \\
\text { trial data and for this reason the trials in question have been re- } \\
\text { moved from the review. }\end{array}$
\end{tabular}

\section{CONTRIBUTIONS OF AUTHORS}

AW ran the searches, screened the citations for eligibility, extracted data, entered data into RevMan and wrote the updated review.

AM screened the citations for eligibility, entered data into RevMan and helped write the updated review.

IR screened citations, extracted data, helped to write the original review.

GS designed and ran the searches, screened the citations for eligibility, contacted authors, extracted data, entered data into RevMan and wrote up the original review.

\section{DECLARATIONS OF INTEREST}

None known.

\section{SOURCES OF SUPPORT}

\section{Internal sources}

- Department of Emergency Medicine, St. Vincent's University Hospital, Dublin 4, Ireland.

\section{External sources}

- NHS R\& D Programme: mother and child health, UK.

- The Higher Specialist Training Scheme in Emergency Medicine, Ireland.

\section{N D X T ERMS}

\section{Medical Subject Headings (MeSH)}

Acute Disease; Brain Injuries [complications] [*drug therapy] [mortality]; Diuretics, Osmotic [*administration \& dosage] [adverse effects]; Intracranial Hypertension [etiology] [ ${ }^{*}$ prevention \& control]; Intracranial Pressure [drug effects]; Mannitol [*administration \& dosage] [adverse effects]; Pentobarbital [administration \& dosage]; Randomized Controlled Trials as Topic; Saline Solution, Hypertonic [administration \& dosage]

\section{MeSH check words}

Humans 